\title{
TOUGHNESS OF ALUMINIUM ALLOY FOAMS
}

\author{
K. Y. G. McCULLOUGH, N. A. FLECK and M. F. ASHBY $\dagger$ \\ Cambridge University Engineering Department, Trumpington Street, Cambridge CB2 1PZ, U.K.
}

(Received 5 March 1999; accepted 14 April 1999)

\begin{abstract}
The fracture behaviour of closed cell aluminium-based foams (trade-name "Alulight") is characterized for the compositions $\mathrm{Al}-\mathrm{Mg} 1-\mathrm{Si} 0.6$ and $\mathrm{Al}-\mathrm{Mg} 1-\mathrm{Si} 10$ (wt\%), and for a relative density in the range $0.1-0.4$. The toughness testing procedures are critically analysed, and the origins of the observed $R$ curve behaviour for metal foams are explored. A major contribution to the observed increasing crack growth resistance with crack advance is in the development of a crack bridging zone behind the crack tip. The crack bridging response is quantified in terms of a crack traction vs extra displacement curve by performing independent tests on deep notch specimens. The area under the bridging traction vs extra displacement curve from the deep notch tests is approximately equal to the measured initiation toughness $J_{\mathrm{IC}}$, in support of the crack bridging concept. A line spring model is then used to interpret the fracture response. The effect of material composition and relative density upon the initiation toughness is measured, and the accuracy of an existing micromechanical model for the fracture toughness of a brittle foam is assessed. Finally, the reduction in tensile and compressive strengths due to the presence of an open hole is determined; it is found that the Alulight foams are notch-insensitive, with the net section strength equal to the unnotched strength. (C) 1999 Acta Metallurgica Inc. Published by Elsevier Science Ltd. All rights reserved.
\end{abstract}

Keywords: Foams; Aluminium alloys; Fracture toughness; Crack growth

\section{INTRODUCTION}

Recent developments in manufacturing methods [14] have allowed for the development of a range of metallic foams made from aluminium alloys, with attractive properties for energy management [5,6], thermal management $[7,8]$ and acoustic absorption [9]. There is a developing literature on the mechanics of foams, see for example Gibson and Ashby [10]. Reviews of earlier work can be found in the articles by Suh and Skochdopole [11] and by Suh and Webb [12], and in the books edited by Wendle [13], Hilyard [14], Hilyard and Cunningham [15] and Banhart [16].

Preliminary tests (for data see Ref. [17]) have shown that for a given density "Alulight" closed cell aluminium foamst are amongst the toughest of the commercial aluminium foams. Alulight is produced by a powder route, and is available as plates or cylinders with a relative density ranging from 0.1 to 0.4 , and in a range of compositions. In the current study, the fracture response and fracture mechanisms have been investigated for $\mathrm{Al}-\mathrm{Si}$ casting alloys with two extremes of silicon content, $\mathrm{Al}-$ $\mathrm{Mg1-Si0.6}$ and $\mathrm{Al}-\mathrm{Mg} 1-\mathrm{Si} 10$ (wt \%).

The uniaxial yield strength and unloading modulus of Alulight have been shown to be close to those predicted for an open cell foam [18]. In this study, we shall address the question whether an

$\dagger$ To whom all correspondence should be addressed.

†Supplier: Mepura Metallpulvergesellschaft m.b.H., Ranshofen, A-5282 Braunau-Ranshofen, Austria. existing micromechanical model for the toughness of an open cell foam is in agreement with the observed fracture toughness of Alulight foams. Gibson and Ashby [10] suggest that for a brittle open cell foam of density $\rho$ made from a solid of density $\rho_{\mathrm{s}}$, the fracture toughness $K_{\mathrm{IC}}$ is related to the relative density $\bar{\rho}=\rho / \rho_{\mathrm{s}}$ by

$$
K_{\mathrm{IC}}=0.65 \sigma_{\mathrm{fs}}(\pi l)^{1 / 2} \bar{\rho}^{3 / 2}
$$

where $\sigma_{\mathrm{fs}}$ is the cell wall $\rightarrow$ edge fracture strength and $l$ the typical cell size. The fracture toughness of rigid polymer foams [19] and reticulated vitreous carbon foams [20] are adequately modelled by this equation providing the foam can be treated as a continuum (crack length $a>10 l$ ). Theoretical models of fracture toughness are not yet available for ductile open cell foams. In order to compare the predictions of equation (1) with toughness data for Alulight foams, it is important to have reliable data for the cell wall $\rightarrow$ edge properties $\rho_{\mathrm{s}}, \sigma_{\mathrm{fs}}$ and $l$. We shall measure the cell wall $\rightarrow$ edge properties independently for Alulight foams, and compare equation (1) with measured data. Since foams can suffer large plastic strains, it is important to define stress and strain measures precisely: we shall employ nominal measures of stress and strain throughout.

\subsection{Aims and structure of this study}

The aim of this study is to measure the toughness properties of Alulight foams, and to interpret these properties in terms of the underlying microstruc- 
ture. We shall show that preliminary $J$-tests on compact tension specimens reveal significant $R$ curve behaviour, with full plastic collapse across the specimen ligament. The validity of applying the $J$ integral to these foams is then investigated for specimens of the adopted size and notch acuity. The bridging cell edges behind the observed (visual) crack tip are found to be a significant cause of the $R$-curve behaviour. Since cell faces fail ahead of the observed crack tip, the observed crack length $a_{0}$ is a somewhat arbitrary measurement. A "zero traction crack length" $a_{\mathrm{Z}}$ is defined as the crack length over which no bridging ligaments exist. $J$-curves developed for the observed crack length and for the zero traction crack length are compared. As expected, the $J$-curve for zero traction crack extension, $J$ $\Delta a_{\mathrm{Z}}$, is less steep than the $J$-curve for the observed crack extension, $J-\Delta a_{0}$. The finite slope of the $J-$ $\Delta a_{\mathrm{Z}}$ curve is thought to be associated with the nonproportional inelastic loading of material elements with crack growth.

An estimate of the crack bridging law is obtained by performing tensile and compressive tests on specimens with two deep edge notches. The measured initiation toughness of the compact tension specimens is found to equal the area under the tractionextra displacement curve of the deep notch tests to within the observed scatter. A simplified, line spring model is then proposed to characterize crack growth in Alulight; for large crack lengths, this model accurately predicts the crack extension and the load supported at a given load-line displacement. However, the one-dimensional model does not capture the effects of non-proportional loading, and a flat $J-\Delta a_{\mathrm{Z}}$ curve is predicted. The effects of relative density, specimen orientation and silicon content on the initiation toughness $J_{\text {IC }}$ are then investigated. The paper concludes with some preliminary measurements of the effect of an open hole on the tensile and compressive strengths.

\section{MATERIAL SPECIFICATION AND EXPERIMENTAL PROCEDURE}

Flat sandwich panels of Alulight foam were obtained with two compositions, Al-Mg1-Si0.6 and $\mathrm{Al}-\mathrm{Mg} 1-\mathrm{Si} 10$ (wt\%). The rectilinear panels were of dimension $145 \mathrm{~mm}$ by $145 \mathrm{~mm}$ by $9 \mathrm{~mm}$, and had solid skins of thickness $0.75 \mathrm{~mm}$ with a foam core [21]. Since the primary focus of this study is the effect of foam density and composition upon toughness, the fully dense skins were removed by wire electro-discharge machining, giving a net specimen thickness $B$ of $7.5 \mathrm{~mm}$ (approximately ten cells). The relative density $\bar{\rho}$ of the as-machined specimens was varied over the range $\bar{\rho}=0.1-0.4$; the precise value of $\bar{\rho}$ for each specimen was obtained by weighing to an accuracy of four significant figures. The mean intercept method was used to measure the cell size $l$. It was found that, for both compositions of foam, the mean cell size varies with relative density according to the relation

$$
l \approx l_{0}(1-2.22 \bar{\rho})
$$

where $l_{0}=2.25 \mathrm{~mm}$. For example, $l \approx 1.5 \mathrm{~mm}$ for a foam of relative density $\bar{\rho}=0.15$, whereas $l \approx 0.5 \mathrm{~mm}$ for a foam of relative density $\bar{\rho}=0.35$.

The density and elastic modulus of the cell wall $\rightarrow$ edge materials are taken to be those of the solid aluminium alloys. The yield strength $\sigma_{\mathrm{ys}}$ was measured by infiltrating the foam with epoxy, and then by micro-indenting the cell edges. For the low silicon content foam, $\mathrm{Al}-\mathrm{Mg} 1-\mathrm{Si0} .6$, the Vickers hardness $H$ is $75 \mathrm{kgf} / \mathrm{mm}^{2}$, corresponding to $\sigma_{\mathrm{ys}} \approx 250 \mathrm{MPa}$ (assuming $\sigma_{\mathrm{ys}} \approx H / 3$ ). For the high silicon content foam, Al-Mg1-Si10, the Vickers hardness is $105 \mathrm{kgf} / \mathrm{mm}^{2}$, corresponding to $\sigma_{\mathrm{ys}} \approx 350 \mathrm{MPa}$. Since the ductility of the foam is low [18], we shall approximate the fracture stress $\sigma_{\mathrm{fs}}$ by $\sigma_{\text {ys. }}$.

Compact tension (CT) specimens of width $W=$ $50 \mathrm{~mm}$ and notch length $a=15 \mathrm{~mm}$ were electrodischarge machined from the Alulight plates. The specimens were reinforced in the vicinity of the loading holes with $3 \mathrm{~mm}$ thick Tufnol facings to prevent pull-out of the loading pins. Initial tests were performed on fatigue pre-cracked specimens; subsequent tests adopted $5 \mathrm{~mm}$ long electro-discharge machined starter notches (of height $0.3 \mathrm{~mm}$ and tip radius $0.15 \mathrm{~mm}$ ) since these gave indistinguishable $J$-curves to within the observed scatter (Section 3.3). All fracture tests were performed at room temperature using a servo-hydraulic mechanical testing machine at a displacement rate of $0.01 \mathrm{~mm} / \mathrm{s}$.

Preliminary measurements of the fracture toughness indicated that the thickness of the compact tension specimens should exceed $109 \mathrm{~mm}$ for a valid measurement of the plane-strain fracture toughness $K_{\mathrm{IC}}$, in accordance with the ASTM plane strain fracture toughness standard E399-90 [22]. With the skins removed the maximum available thickness was $7.5 \mathrm{~mm}$. Consequently, the $J$-integral test procedure, as specified in ASTM E813-89 [23], was adopted. A posteriori checks confirmed that the specimens were sufficiently large to satisfy the size requirements of the $J$-integral test method. The plane-strain fracture toughness $K_{\mathrm{IC}}$ is related to the initiation toughness $J_{\mathrm{IC}}$ by the well-known relation (see for example Ref. [24])

$$
K_{\mathrm{IC}}=\sqrt{J_{\mathrm{IC} E^{\prime}}}
$$

where $E^{\prime} \equiv E /\left(1-v^{2}\right)$ is the plane strain Young's modulus, and the Poisson ratio $v$ is assumed to be equal to 0.3 , as recommended by Ashby et al. [17]. The Young's modulus $E$ is measured from the elastic unloading compliance of the compact tension specimens, following ASTM E813-89 [23]. Measurements of $J_{\mathrm{IC}}$ were performed using the 


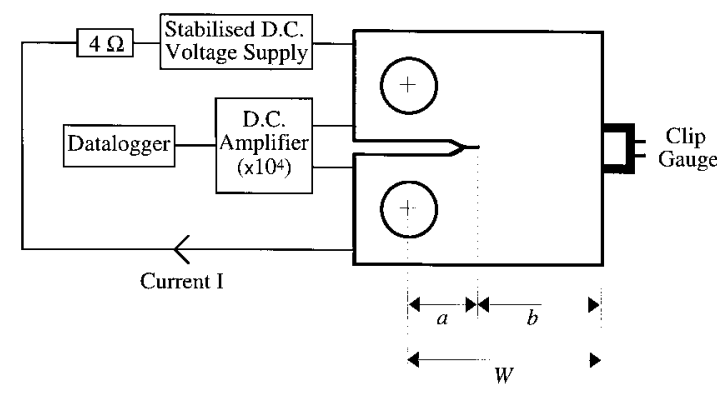

Fig. 1. J-test apparatus.

single specimen technique (see ASTM E813-89 for details); the $J$-integral vs crack extension $\Delta a$ response was calculated from the load $P$ vs load-line displacement $u$ response of the specimen.

An evaluation of the $J$-integral relies upon an accurate measurement of crack growth. The d.c. potential drop method was used to monitor crack extension since, for fully dense metals, it can determine crack growth to an accuracy of about $0.01 \mathrm{~mm}$ [25]. The apparatus adopted here is illustrated in Fig. 1. To ensure accurate potential drop readings the specimen was insulated from the testing machine by using Tufnol loading pins. A constant current of $3 \mathrm{~A}$ was applied by using a stabilized d.c. voltage supply and a $4 \Omega$ series resistor, which is large compared with that of the specimen (the Alulight foam of relative density $\bar{\rho}=0.1$ gave rise to a specimen resistance of $2.1 \mathrm{~m} \Omega$, whilst a relative density $\bar{\rho}=0.3$ gave rise to a specimen resistance of $0.7 \mathrm{~m} \Omega$ ). The usual steps were taken to minimize thermal drift and maximize resolution. $\dagger$

The relationship between the potential drop across probe wires spot-welded to the specimen and the crack length was found using the electrical analogue method as described by Smith [27]. Briefly, a 5:1 scale model of the specimen was made from aluminium foil, and a constant current was supplied via a constant voltage supply and variable resistor. Crack growth was simulated by razor cutting the foil, and the potential drop output across the notch was measured with a millivolt meter. The calibration was repeated three times to ensure accuracy. The relationship between potential drop across the notch and the length of the razor was plotted and a least squares quadratic regression was fitted for the normalized crack length $(a / W)$ in

$\dagger$ The leads were positioned as recommended by Halliday and Beevers [26], with the potential drop wires spot welded across the notch mouth at a distance of $5 \mathrm{~mm}$ from the centreline of the specimen. These wires, insulated with Rockwool to minimize thermal drift, were twisted together to minimize inaccuracies due to random electromotive forces (EMFs), and were fed into a stable d.c. amplifier of gain $10^{4}$. The amplifier magnified the potential difference across the crack from $\approx 0.4 \mathrm{mV}$ to $\approx 4 \mathrm{~V}$. A low pass filter of time constant $1 \mathrm{~s}$ reduced electrical noise. The output from this amplifier was fed into a computerized datalogger. terms of the normalized voltage $\left(V / V_{0}\right)$

$$
\frac{a}{W}=-0.79+1.37\left(\frac{V}{V_{0}}\right)-0.27\left(\frac{V}{V_{0}}\right)^{2}
$$

where $V_{0}$ is the voltage across the specimen for a normalized crack length $a / W=0.3$. The correlation coefficient for this curve fit is $R^{2}=0.99947$. Equation (4) deviates by less than $2 \%$ from the calibrations of Fleck [25] and of Irving and Kurzfeld [28].

Compliance techniques were used to check the accuracy of the potential drop method, as follows. An electrically-insulated back face clip gauge was fastened to each specimen, and the specimens were periodically unloaded by at least $10 \%$ and reloaded during the toughness tests. The back face clip gauge and the displacement transducer of the test machine allowed for two additional methods of determining crack length, namely the back face strain technique recommended by Richards and Deans [29], and the load-line compliance technique recommended by the $J_{\text {IC }}$ standard ASTM E813-89 [23].

\section{PRELIMINARY FRACTURE TESTS}

\subsection{Apparent fracture response}

Typical $J-\Delta a$ curves are shown in Fig. 2 for both the $\mathrm{Al}-\mathrm{Mg} 1-\mathrm{Si} 0.6$ and $\mathrm{Al}-\mathrm{Mg} 1-\mathrm{Si} 10$ foams, of relative density $\bar{\rho}=0.17$. The crack extension has been calculated by both the potential drop method and back face compliance, and we find that the two techniques give the same crack extension at any given load and the same $J$-curves. This result is not immediately expected, as the mechanical and electrical properties need not change in direct proportion with increasing damage. The magnitude of back face strain in these fracture tests confirm that the

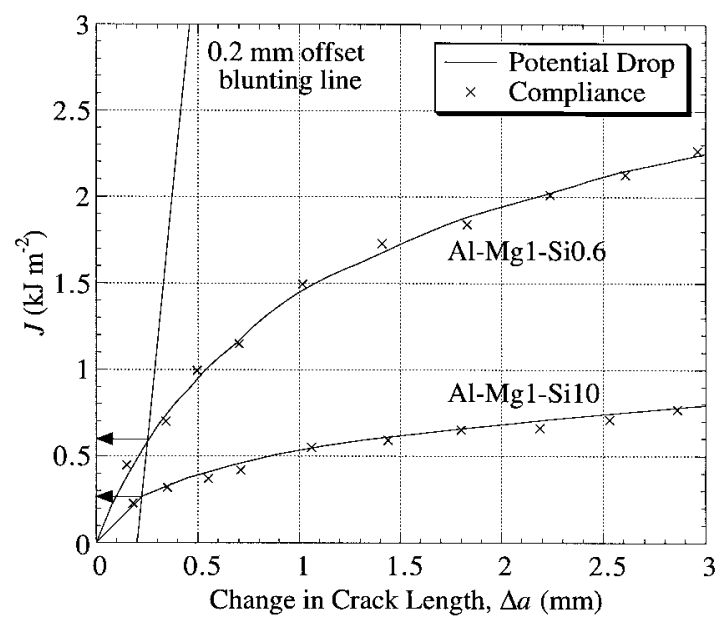

Fig. 2. Comparison of $J$-curves for $\mathrm{Al}-\mathrm{Mg} 1-\mathrm{Si} 0.6$ and $\mathrm{Al}-$ $\mathrm{Mg} 1-\mathrm{Si} 10$ (wt\%). Results are shown for compact tension specimens with relative density $\bar{\rho}=0.17$. The crack length is measured using unloading compliance (back face strain gauge) and the d.c. potential drop method. 
foams suffer "full plastic collapse" across the specimen ligament: for example, for the specimens reported in Fig. 2, the back face strain is of the order of $1 \%$ at an inferred crack extension $\Delta a=2 \mathrm{~mm}$. We note in passing that the $R$-curves observed in Fig. 2 are qualitatively similar to those reported for Alporas aluminium alloy foam [30]. We further note that the $R$-curve of the $\mathrm{Al}-\mathrm{Mg1}-$ $\mathrm{Si} 0.6$ foam is about three times the magnitude of that for $\mathrm{Al}-\mathrm{Mg} 1-\mathrm{Si} 10$ at the same relative density. This is consistent with the higher ductility reported for the low silicon foam [18].

The crack blunting lines on the $J-\Delta a$ plots are given by $J=2 \sigma_{\mathrm{pl}} \Delta a$, where $\sigma_{\mathrm{pl}}$ is the tensile yield strength of the foam, as measured in Ref. [18]. The intercept of these blunting lines with the $J$-curve gives a provisional value of $J_{\mathrm{IC}}$ (designated $\left.J_{\mathrm{Q}}\right)=0.60 \mathrm{~kJ} / \mathrm{m}^{2}$ for the $\mathrm{Al}-\mathrm{Mg} 1-\mathrm{Si} 0.6$ foam and $J_{\mathrm{Q}}=0.27 \mathrm{~kJ} / \mathrm{m}^{2}$ for the $\mathrm{Al}-\mathrm{Mg} 1-\mathrm{Si} 10$ foam. The quantity $25 J_{\mathrm{Q}} / \sigma_{\mathrm{pl}}$ (equal to $2.28 \mathrm{~mm}$ for the $\mathrm{Al}-$ $\mathrm{Mg} 1-\mathrm{Si} 0.6$ foam and $1.81 \mathrm{~mm}$ for the $\mathrm{Al}-\mathrm{Mg} 1-\mathrm{Si} 10$ foam) is less than the specimen thickness $(7.5 \mathrm{~mm})$ and less than the initial ligament size $(30 \mathrm{~mm})$, justifying the identification of $J_{\mathrm{Q}}$ with $J_{\text {IC. }}$. The elastic unloading compliance gives values for the plane strain Young's modulus $E^{\prime}=1.94$ and $1.42 \mathrm{GPa}$ for the $\mathrm{Al}-\mathrm{Mgl}-\mathrm{Si0} 6$ and $\mathrm{Al}-\mathrm{Mg} 1-\mathrm{Si} 10$ foams, respectively, and so from equation (3) the corresponding plane-strain fracture toughnesses are $K_{\mathrm{IC}}=1.08$ and $0.62 \mathrm{MN} / \mathrm{m}^{3 / 2}$.

\subsection{Validity of applying the J-integral to foams}

In general, the $J$-integral cannot be used to characterize significant amounts of crack growth due to the occurrence of non-proportional plastic loading near the crack tip. The path-independence of $J$ rests upon the assumption that the material response can be represented by a non-linear elastic solid, and this assumption breaks down under nonproportional loading of material elements [31]. However, under restricted circumstances, the loading can be shown to be nearly proportional and small amounts of crack growth can be analysed. Hutchinson and Paris [31] have shown that for $J$ controlled growth two conditions must be satisfied

$$
\begin{gathered}
\text { Condition (i), } \Delta a \ll R \\
\text { Condition (ii), } \omega \equiv \frac{b}{D}=\frac{b}{J} \frac{\mathrm{d} J}{\mathrm{~d} a} \gg 1
\end{gathered}
$$

where $R$ is the size of the region in which the $J$-field of deformation theory has dominance, $b$ is the uncracked ligament and $D$ equals $J(\mathrm{~d} J / \mathrm{d} a)^{-1}$.

The $J-R$ standard, ASTM E1152-87 [32], stipulates the first condition by restricting the maximum crack extension capacity of a compact tension specimen to $\Delta a=0.1 b_{0}(=3 \mathrm{~mm}$ here, as the initial ligament $\left.b_{0}=30 \mathrm{~mm}\right)$. Next, consider the second condition, as stated in equation (6). For compact tension specimens Shih et al. [33] suggest that a value $\omega>10$ is sufficient to satisfy equation (6). From Fig. $2, \quad D \approx 1 \mathrm{~mm}$, giving $\omega \approx 30$ and we deduce that the $J$-curves meet the requirements of ASTM E1152-87. However, we shall show that the occurrence of a large zone of crack bridging will dictate a reinterpretation of the measured $J-\Delta a$ curves.

Curves of $J$ vs $\Delta a$ are plotted in Fig. 3 for a crack extension $\Delta a \leq 3 \mathrm{~mm}$, using three different recommended procedures for the evaluation of $J$ : the $J_{\text {IC }}$ standard (ASTM E813-89), the $J-R$ standard (ASTM E1152-87) and the modified $J$-integral, $J_{\mathrm{M}}$ [34]. The difference between the $J$-curves from the three procedures is less than the experimental scatter. Consequently, the most straightforward method, as laid down by ASTM E813-89, is adopted in the sequel.

\subsection{Effect of specimen size and notch tip acuity on the measured toughness}

The effect of specimen size was explored by measuring the $R$-curves for geometrically similar specimens of width $W=50$ and $100 \mathrm{~mm}$, made from nominally identical foam of composition $\mathrm{Al}-$ $\mathrm{Mg} 1-\mathrm{Si} 0.6$ and relative density $\bar{\rho}=0.27$. The $J$ curves are indistinguishable within material scatter, as shown in Fig. 4. We conclude that a specimen size of $W=50 \mathrm{~mm}$ is adequate for our purposes. Next, consider the effect of notch root radius upon the measured toughness. It is expected that the cellular microstructure blunts the notch tip when the diameter $d$ of the notch tip is less than the cell diameter $l$. To explore this, we performed additional tests on the $\mathrm{Al}-\mathrm{Mg} 1-\mathrm{Si} 0.6$ foam, of $\bar{\rho}=0.27$ and cell size $l=0.9 \mathrm{~mm}$. The notch root diameter $d$ was varied from a dimension of the order of microns by fatigue pre-cracking of the specimen to a dimension $d=4 \mathrm{~mm}$ by electro-discharge machining a prenotch. We find that there is no effect of notch root diameter upon the measured $J$-curve provided $d<l$,

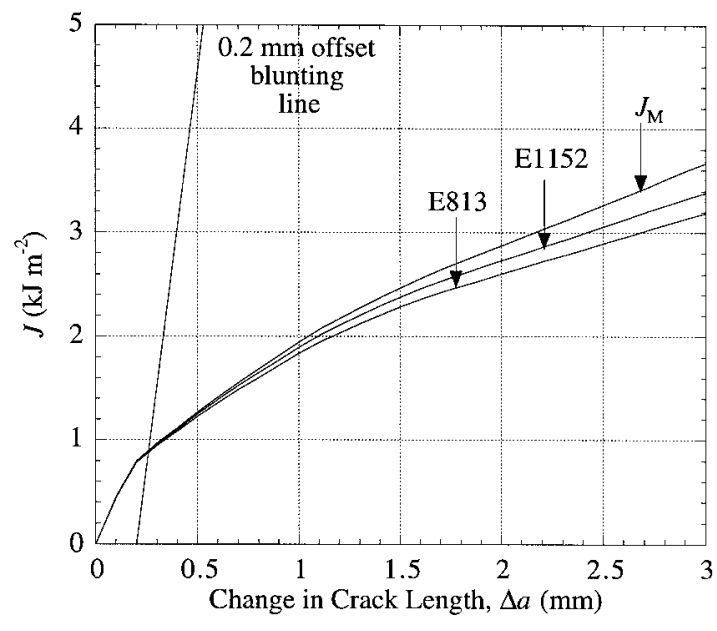

Fig. 3. Comparison of $J$-curves using ASTM E813-89, E1152-87 and the $J_{\mathrm{M}}$ method [33]. Compact tension specimen of composition Al-Mgl-Si0.6 with $\bar{\rho}=0.21$. 


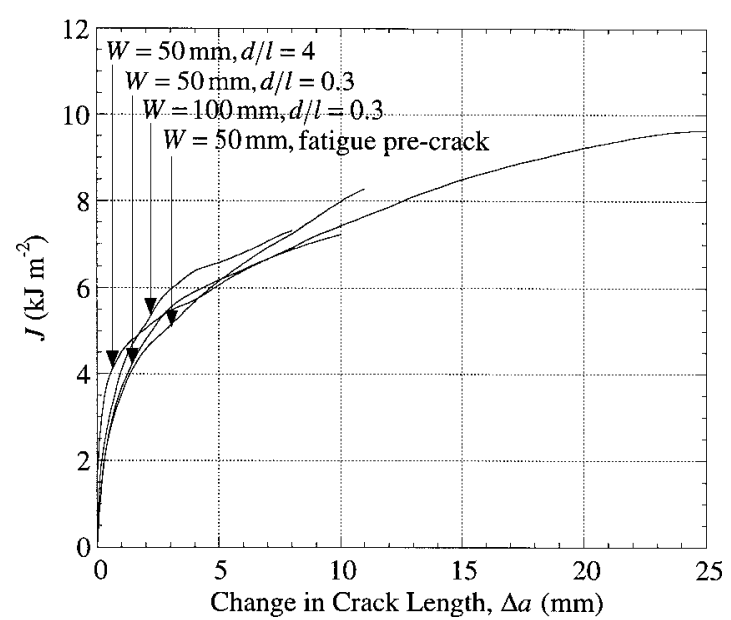

Fig. 4. Effect of specimen size and notch acuity on the measured toughness. Compact tension specimens of composition $\mathrm{Al}-\mathrm{Mgl}-\mathrm{Si} 0.6$ with $\bar{\rho}=0.27$. Most tests were stopped with $\Delta a \approx 10 \mathrm{~mm}$ to allow for saw-cutting and SEM examination, as described in Section 3.4 .

but an increased initial toughness is observed for $d>l$, see Fig. 4 .

\subsection{The bridging zone behind the inferred crack tip}

Travelling microscope observations in the preliminary $J$-tests revealed that crack bridging ligaments exist in the wake of the advancing crack tip. In order to determine the significance of the bridging zone, several $J$-tests were interrupted after some crack advance. The specimen was unloaded and a fine $(0.4 \mathrm{~mm}$ wide) jeweller's saw blade was used to remove the crack wake to the inferred crack tip (from potential drop and compliance techniques). Figure 5 shows a typical load-displacement curve for a $0.6 \% \mathrm{Si}$ specimen which has been sawcut twice. The saw-cuts have two immediately apparent effects: the collapse load of the specimen

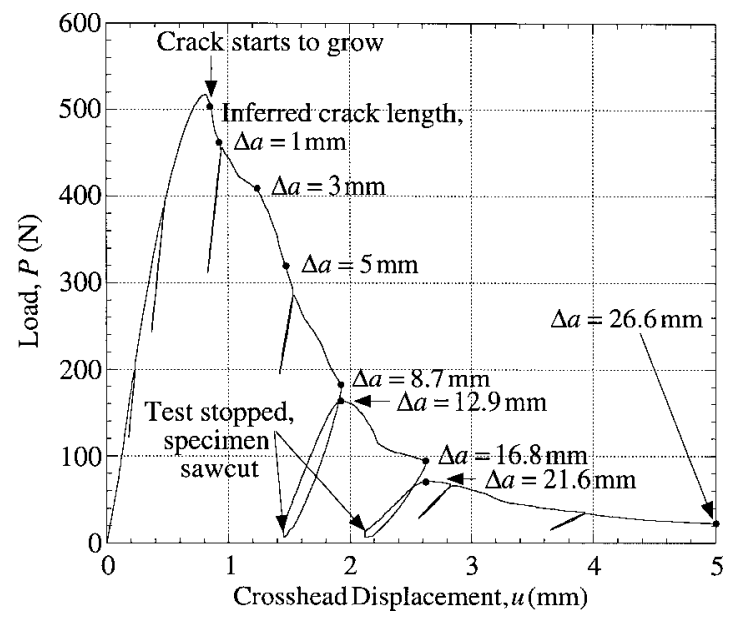

Fig. 5. Typical load vs cross-head displacement curve for a compact tension specimen of composition $\mathrm{Al}-\mathrm{Mg} 1-\mathrm{Si0} 6$ with $\bar{\rho}=0.17$. drops (from 180 to $163 \mathrm{~N}$, and from 92 to $71 \mathrm{~N}$ ) and the inferred crack length increases (from 28.7 to $32.9 \mathrm{~mm}$, and from 36.8 to $41.6 \mathrm{~mm}$ ). These observations suggest that crack bridging ligaments form in the Alulight foam.

In order to investigate the length of the load-carrying bridging zone in the crack wake, tests were performed where the crack wake was progressively removed by a jeweller's saw and the resulting collapse load of the specimen was measured. Tests were performed on specimens of composition $\mathrm{Al}-$ $\mathrm{Mg} 1-\mathrm{Si} 0.6$ for $\bar{\rho}$ in the range $0.13-0.25$. The test details and typical results are shown in Fig. 6. Briefly, a long crack was advanced from the notch root (typically $\Delta a=19 \mathrm{~mm}$ for an initial crack length $a=20 \mathrm{~mm}$ and an initial ligament $b=30 \mathrm{~mm})$ and the load $P_{0}$ was noted. The specimen was unloaded, a saw-cut was extended over a length $x=3 \mathrm{~mm}$ ahead of the initial notch root, the specimen was reloaded, and the collapse load $P$ of the specimen was recorded. This process was repeated by removing an increasing length $x$ of crack wake from the notch root. For the specimen shown in Fig. 6, with $\bar{\rho}=0.25$ and a mean cell size $l \approx 1 \mathrm{~mm}$, we deduce that the normalized strength $P / P_{0}$ only drops when crack wake over a length $x=14 \mathrm{~mm}$ has been removed: we conclude that the bridging zone extends approximately four-five cells along the crack wake back from its tip.

\subsection{Micromechanisms of crack initiation and propa- gation}

Immediately beyond peak load in the toughness tests small cracks initiate at or near the edge corners of the notch tip, in similar fashion to that reported for an Alporas foam [30]. A dominant crack then propagates approximately along the centreline of the specimen, apparently following the weakest path from cell to cell. The crack growth

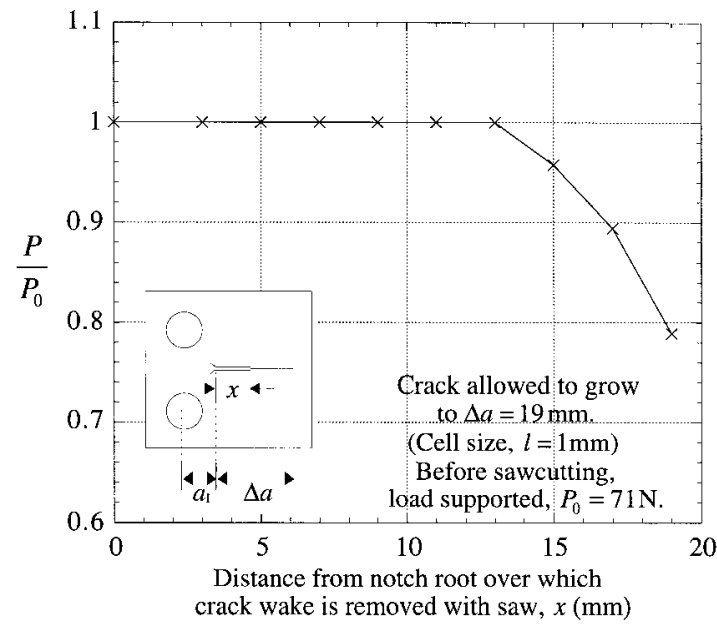

Fig. 6. Effect of removal of crack wake on collapse load of a compact tension specimen of composition Al-Mg1Si0.6 with $\bar{\rho}=0.25$. 


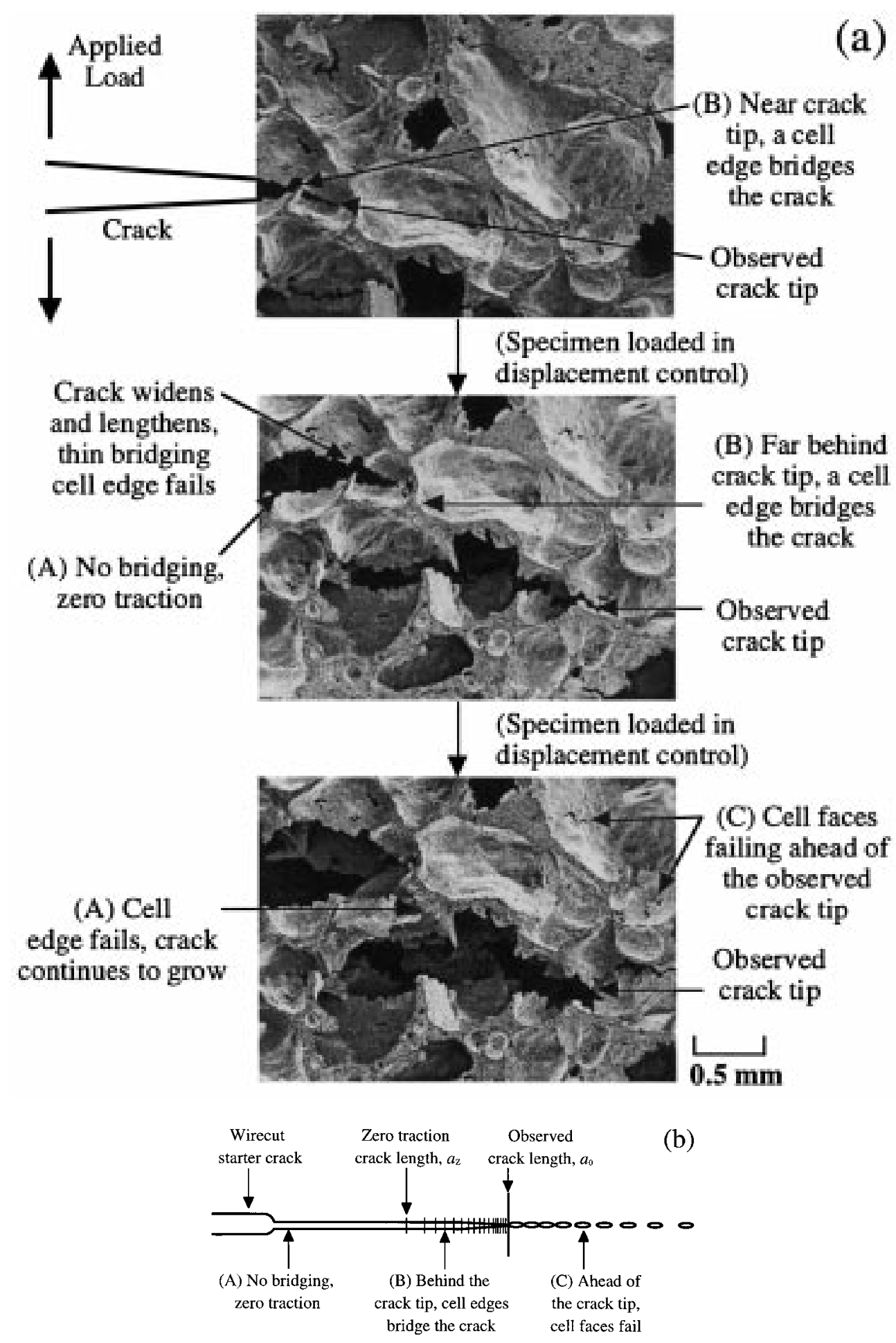

Fig. 7. (a) Progressive cracking of a compact tension specimen of composition $\mathrm{Al}-\mathrm{Mg} 1-\mathrm{Si} 0.6$ with $\bar{\rho}=0.30$. The fracture toughness test was periodically interrupted and the specimen was observed in a scanning electron microscope (SEM). The states of cracking (A)-(C) are defined in (b). (b) Schematic of crack growth in the specimen of (a), showing the various states of cracking ahead of and in the wake of the crack tip.

mode within the cell faces resembles plane-stress crack growth in thin sheets.

Scanning electron microscope (SEM) micrographs are shown in Fig. 7(a) for a crack propagating from left to right in an $\mathrm{Al}-\mathrm{Mg} 1-\mathrm{Si} 0.6$ specimen of $\bar{\rho}=0.30$. An accompanying schematic of crack growth in Alulight is shown in Fig. 7(b). It is clear from these micrographs (and also from travelling 
microscope measurements made during the toughness tests) that the crack bridging zone, comprised of torn cell faces and intact cell edges, exists over a length of about four cells between the observed crack tip and the zero traction crack tip. Ahead of the observed crack tip, the progressive failure of cell faces is evident.

\subsection{A comparison of observed, inferred and zero} traction crack lengths

The observed, inferred and zero traction crack lengths in a typical $J$-test are compared in Fig. 8 for a Al-Mg1-Si0.6 specimen with cell size $l \approx 1 \mathrm{~mm}(\bar{\rho}=0.25)$. Recall that the observed crack length $a_{0}$ is measured by travelling microscopy and the inferred crack length $a$ is deduced from potential drop and compliance methods. From the results of Sections 3.4 and 3.5 the bridging zone is about four cell sizes, and so the zero traction crack length $a_{\mathrm{Z}}$ is taken to be shorter than the inferred crack length $a$ by this amount. Initially, the inferred crack length increases without any visual signs of cracking. This is consistent with cell faces failing ahead of the observed crack tip, increasing the compliance and electrical resistance and thus increasing the inferred crack length [see the micrographs, Fig. 7(a)]. As the crack extends the discrepancy between the observed and inferred crack lengths decreases. This is consistent with the accumulation of ligaments bridging the wake of the observed crack: these ligaments carry load and electrical current, and cause a progressive decrease in the difference between the inferred and observed crack lengths. When the crack has grown visually by $\Delta a_{0} \approx 10 \mathrm{~mm}$ the overestimation of crack length from failed cell faces ahead of the observed crack tip and the underestimation of crack length from bridging ligaments behind the observed crack tip approximately cancel each other. The crack wake is

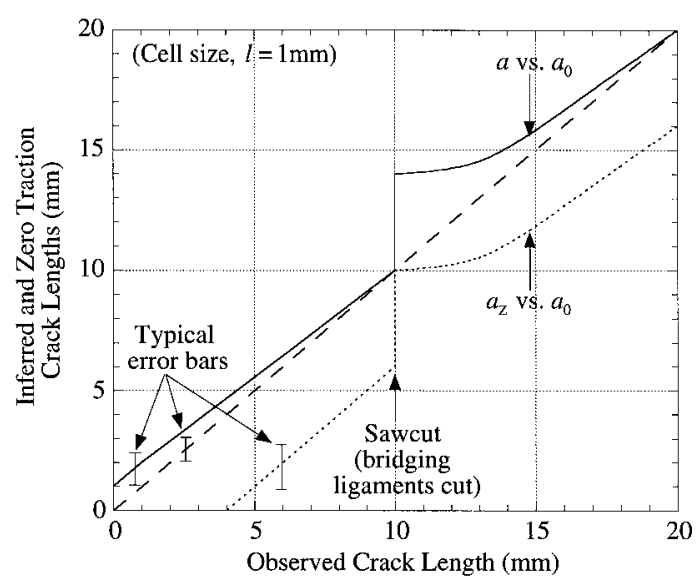

Fig. 8. Comparison of inferred crack length $a$ (by potential drop and unloading compliance), and zero traction crack length $a_{\mathrm{Z}}$ with the observed crack length $a_{0}$, for a compact tension specimen of composition $\mathrm{Al}-\mathrm{Mg} 1-\mathrm{Si} 0.6$ with $\bar{\rho}=0.25$. then removed by manually saw-cutting to the inferred crack tip. This has the effect of increasing the inferred crack length by $4-5 \mathrm{~mm}$ (Fig. 8): the ligaments which caused the underestimation of crack length have been removed but the failed cell faces which caused the overestimation remain ahead of the crack tip.

\subsection{J-curves, using the zero traction crack length}

It is difficult to be precise about the location of the crack tip, as it is ensconced by damaged foam. The zero traction crack length provides a physical definition of crack length, but it is difficult to determine experimentally the traction-free length of the crack. A comparison of $J$-curves using inferred and zero traction crack lengths is shown in Fig. 9 for a $\mathrm{Al}-\mathrm{Mg} 1-\mathrm{Si} 0.6$ specimen. Thus, the curves give the remote value of $J$ corresponding to a crack length defined in different ways.

From the inferred $J$-curve of Fig. 9, $J_{\mathrm{IC}}=1.60 \mathrm{~kJ} / \mathrm{m}^{2}, \quad D \bumpeq 1 \quad \mathrm{~mm}$ and $\omega \approx 30 \quad($ see equation (6)). From the zero traction curve, $J_{\mathrm{Q}}=5.82 \mathrm{~kJ} / \mathrm{m}^{2} ; D \approx 10 \mathrm{~mm}$ and $\omega \approx 3$. The small positive slope of the traction-free $J$-curve is thought to be due to non-proportional loading of material elements in the vicinity of the crack tip. The value $J_{\mathrm{Q}}$ for the traction-free crack is designated $J_{\mathrm{IC}}$ and is used to characterize Alulight's resistance to crack initiation provided that the specimen size criteria are met: $B$ and $b_{0}>25 J_{\mathrm{Q}} / \sigma_{\mathrm{pl}}$, as specified in ASTM E813-89 [23] and E1152-87 [32]. Typically $25 J_{\mathrm{Q}} / \sigma_{\mathrm{pl}} \approx 12 \mathrm{~mm}$, thus the ligament size criterion is met. Unfortunately, the thickness criterion is not met; the maximum available specimen thickness is $B \approx 7.5 \mathrm{~mm}$. Further studies are required to determine whether the thickness requirement $B>$ $25 J_{\mathrm{Q}} / \sigma_{\mathrm{pl}}$ is appropriate for metallic foams. Fleck and Smith [35] found experimentally that this thick-

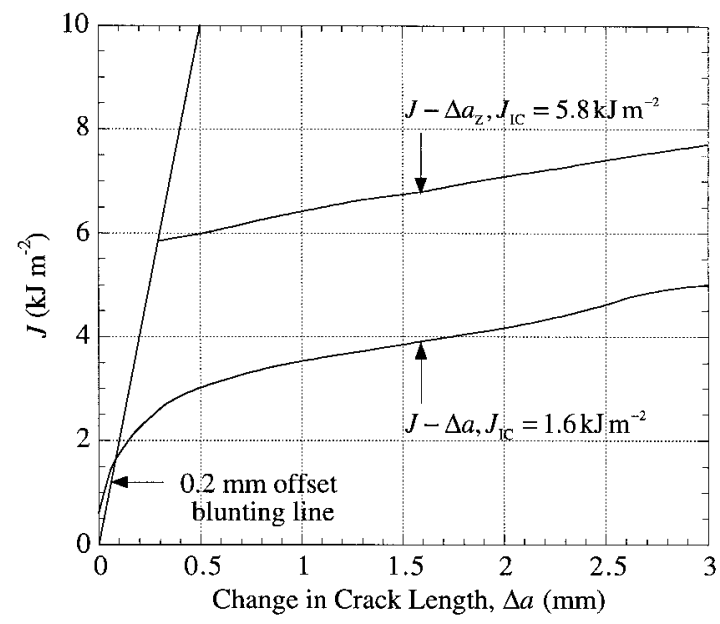

Fig. 9. Comparison of the $J$-curve measured for an inferred crack length $\Delta a$ and for a zero traction crack length $\Delta a_{\mathrm{Z}}$. Compact tension specimen of composition $\mathrm{Al}$ $\mathrm{Mg} 1-\mathrm{Si} 0.6$ with $\bar{\rho}=0.27$. 
ness criterion can be relaxed for sintered metals of relative density $\bar{\rho} \approx 0.85$ : the plane strain fracture toughness is attained for much thinner specimens than stipulated by the standard criterion for fully dense metals.

\section{EFFECT OF RELATIVE DENSITY UPON INITIATION TOUGHNESS}

Fracture toughness tests were performed on specimens of the $0.6 \% \mathrm{Si}$ foam over a density range $\bar{\rho}=0.13-0.32$. The measured values for $J_{\text {IC }}$ and Young's modulus $E$ (from ASTM E813-89), together with the inferred values for plane-strain fracture toughness $K_{\mathrm{IC}}$ [from equation (3)] are summarized in Fig. 10(a). The crack extension was measured by the d.c. potential drop method, and the initiation toughness was taken as the intersection of the $J-\Delta a$ curve and the blunting line. As

(a)

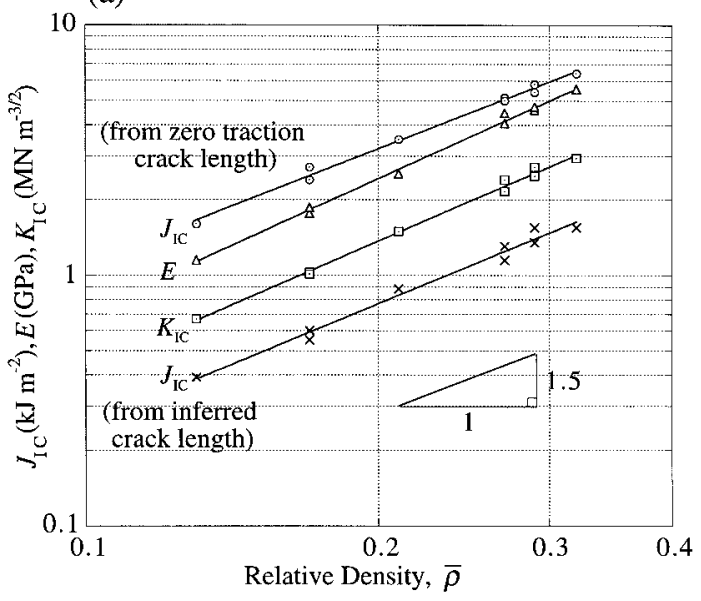

(b)

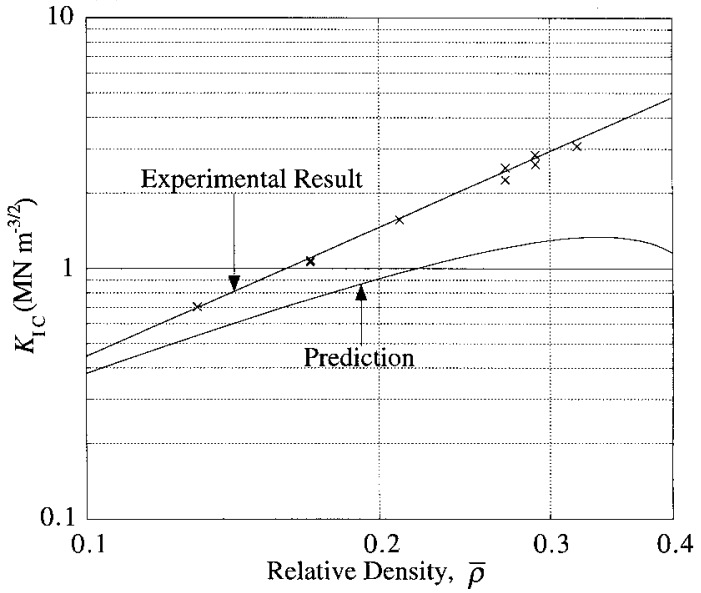

Fig. 10. (a) Effect of density on the toughness and Young's modulus of $\mathrm{Al}-\mathrm{Mg} 1-\mathrm{Si} 0.6$. (b) Comparison of predicted fracture toughness from equation (1) with measured values, for $\mathrm{Al}-\mathrm{Mg} 1-\mathrm{Si} 0.6$. The curvature of the predicted curve is due to the dependence of cell size $l$ upon relative density $\bar{\rho}$, see equation (2). expected, the toughness $J_{\text {IC }}$ increases with relative density $\bar{\rho}$. For the density range $\bar{\rho}=0.13-0.32$ the following power law fits adequately describe the data of Fig. 10(a).

Toughness from inferred crack length:

$$
\begin{aligned}
J_{\mathrm{IC}} & =10 \bar{\rho}^{1.60}\left(\mathrm{~kJ} / \mathrm{m}^{2}\right), \\
E & =42 \bar{\rho}^{1.77}(\mathrm{GPa}) \text { and } \\
K_{\mathrm{IC}} & =22 \bar{\rho}^{1.69}\left(\mathrm{MN} / \mathrm{m}^{3 / 2}\right) .
\end{aligned}
$$

Toughness from zero traction crack length:

$$
\begin{aligned}
J_{\mathrm{IC}} & =37 \bar{\rho}^{1.52}\left(\mathrm{~kJ} / \mathrm{m}^{2}\right), \\
E & =42 \bar{\rho}^{1.77}(\mathrm{GPa}) \text { and } \\
K_{\mathrm{IC}} & =41 \bar{\rho}^{1.65}\left(\mathrm{MN} / \mathrm{m}^{3 / 2}\right) .
\end{aligned}
$$

The inferred fracture toughness $K_{\mathrm{IC}}$ of the $0.6 \% \mathrm{Si}$ foam is compared with equation (1) for brittle open cell foams in Fig. 10(b). The prediction is not a simple power law relation due to the dependence of cell size $l$ upon $\bar{\rho}$. For $\bar{\rho}=0.13$ the measured toughness is approximately 1.25 times the predicted value; as the density increases the curves diverge so that at $\bar{\rho}=0.32$ the discrepancy is approximately a factor of 2.25. We conclude that a more accurate micromechanical model for the fracture toughness of ductile metallic foams is required. The value of the power law exponent for $K_{\mathrm{IC}}$ as a function of $\bar{\rho}$ is close to the value of 1.5 expected for an open cell foam, and is far from the value of unity expected for a closed cell foam. This supports the general finding that current commercial aluminium alloy foams have properties much closer to those of an open cell foam than those of a closed cell foam [36].

\section{MEASURED CRACK BRIDGING LAW}

The normal traction vs crack opening displacement associated with plasticity and tearing of the crack bridging ligaments was estimated by performing independent tensile and compressive tests on deep edge notch specimens, as sketched in Fig. 11(a). It is assumed that the crack bridging law is given by the average traction on the net section of deep notch specimens vs the additional axial displacement across the mid-plane associated with plasticity and cracking. This assumption is reasonable if the degree of plastic constraint in the two geometries is similar and the inelastic zone extends uniformly across the net section of the double edge notch specimens.

Double edge notch specimens of length $2 L=70 \mathrm{~mm}$, width $2 W=20 \mathrm{~mm}$ and thickness $B \approx 7.5 \mathrm{~mm}$ were spark machined from the $0.6 \% \mathrm{Si}$ foam, for $\bar{\rho}$ in the range $0.1-0.4$. The notch length $a$ was varied over the range $a / W=0.2-0.6$. Clip 
(a)

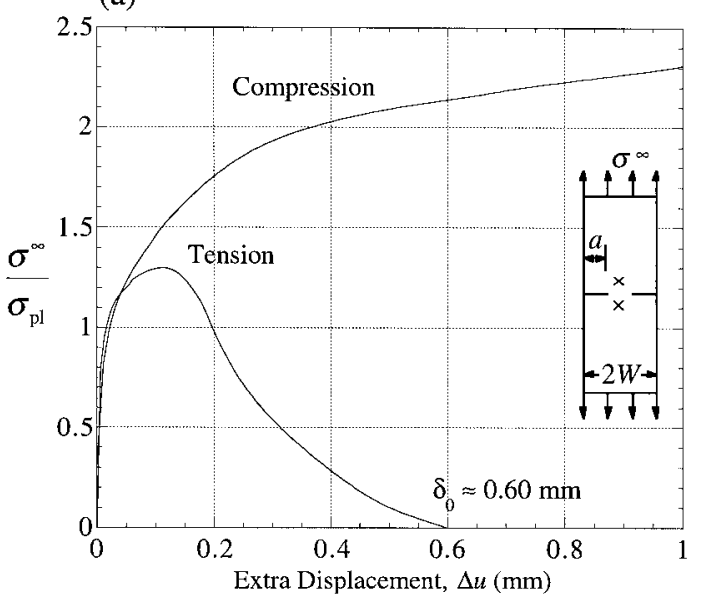

(b)

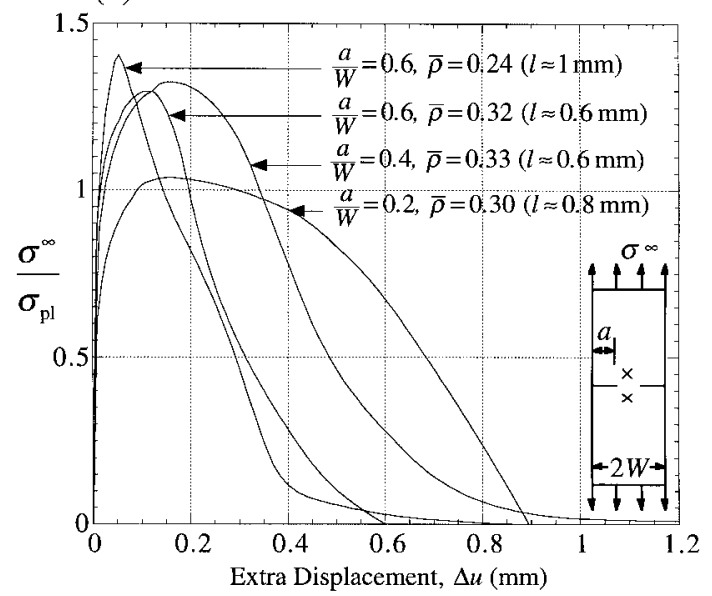

Fig. 11. (a) Comparison of measured crack bridging law in tension and in compression, for deep notched longitudinal orientation $\mathrm{Al}-\mathrm{Mg} 1-\mathrm{Si} 0.6$, with relative density $\bar{\rho}=0.32$, cell size $l \approx 0.65 \mathrm{~mm}$ and $a / W=0.6$. The crosses marked on the specimen in the inset define the gauge length of the clip gauge. The wire-cut notches were $0.3 \mathrm{~mm}$ wide in the tensile specimens and $2 \mathrm{~mm}$ high in the compressive specimens. (b) Effect of notch length $a$ and relative density $\bar{\rho}$ upon the crack bridging law of $\mathrm{Al}-$ Mg1-Si0.6 foam for tensile loading in the longitudinal direction.

gauges, with gauge lengths 6 and $10 \mathrm{~mm}$, were mounted axially along the mid-plane of the specimens to measure the extra displacement associated with plasticity and tearing of the net section between the notches, under tensile and compressive loading. The gauges were placed symmetrically about the net section. The compressive loading platens were lubricated with PTFE spray in order to minimize friction between the specimen and the platens. Typical results for deep notched high density specimens are summarized in Fig. 11(a); the effects of notch length $a$ and relative density $\bar{\rho}$ on the tensile crack bridging law are shown in Fig. 11(b). The results shown are for tests performed with specimens aligned in the longitudinal direction of cast- ing; a similar response was observed for specimens tested in the transverse direction.

In both Figs 11(a) and (b) the net section stress $\sigma_{\text {net }}$, normalized by the unnotched yield strength $\sigma_{\mathrm{pl}}$ of the foam, is plotted against the extra displacement $\Delta u$ associated with plasticity and cracking between the clip gauge anvils. This extra displacement is calculated as $\Delta u=u-u_{\mathrm{el}}$, where $u_{\mathrm{el}}$ is the elastic load-line displacement. The results for $\Delta u$ were similar for the clip gauges of gauge length 6 and $10 \mathrm{~mm}$ : the extra displacement is due to tearing of the net section. Some plastic constraint was observed in tension and compression: the tensile peak stress $\sigma_{\mathrm{p}}$ increased with notch length $a / W$ in tension to a value $\sigma_{\mathrm{p}} \approx 1.3 \sigma_{\mathrm{pl}}$ at $a / W=0.6$, and the compressive peak stress increased to $\sigma_{\mathrm{p}} \approx 1.8 \sigma_{\mathrm{pl}}$ at $a / W=0.6$. In the tensile tests with high density specimens $(\bar{\rho}>0.3)$ the extra displacement at failure is approximately equal to the cell size, whereas for lower density specimens the extra displacement at failure is somewhat less than $l$.

\section{LINE SPRING MODEL OF THE FRACTURE RESPONSE}

The following simple crack bridging model is proposed for crack advance in the Alulight foam. A Dugdale-type crack bridging law is assumed for both tensile and compressive loading: the bridging traction has the constant value $\sigma_{\mathrm{pl}}$ in tension and $-\sigma_{\mathrm{pl}}$ in compression. The traction is assumed to drop stepwise to zero at a critical tensile opening $u_{\mathrm{c}}$, whereas in compression the traction is held constant for all values of crack face overlap. This crack bridging law is a simplified representation of the traction vs extra displacement curves shown in Fig. 11.

It has already been noted that full plastic collapse occurs across the ligament of the compact tension fracture specimens. This leads to the following idealization for large-scale bridging: the ligament of the specimen is treated as a plastic hinge, with bending stresses equal to $\pm \sigma_{\mathrm{pl}}$, see Fig. 12. A moment balance gives

$$
P\left(W-\frac{c}{2}\right)=\frac{\sigma_{\mathrm{pl}} B c^{2}}{4}
$$

where $P$ is the applied load, $W$ the width of the specimen, $c$ the uncracked ligament (from the zero traction crack length) and $B$ the thickness of the specimen. This relationship is compared with typical $P-c$ data from a $0.6 \% \mathrm{Si}$ specimen in Fig. 13(a). By plotting $P(W-c / 2)$ against $B c^{2} / 4$ the predicted yield strength of the foam can be deduced and compared to the yield strength from uniaxial tests [18]. There is reasonable agreement between the experimental data and equation (9) for large crack lengths: the model predicts a yield strength $\sigma_{\mathrm{pl}} \approx 9 \mathrm{MPa}$, which is $8 \%$ less than the measured value of $\sigma_{\mathrm{pl}} \approx 9.8 \mathrm{MPa}$. We conclude that the one- 


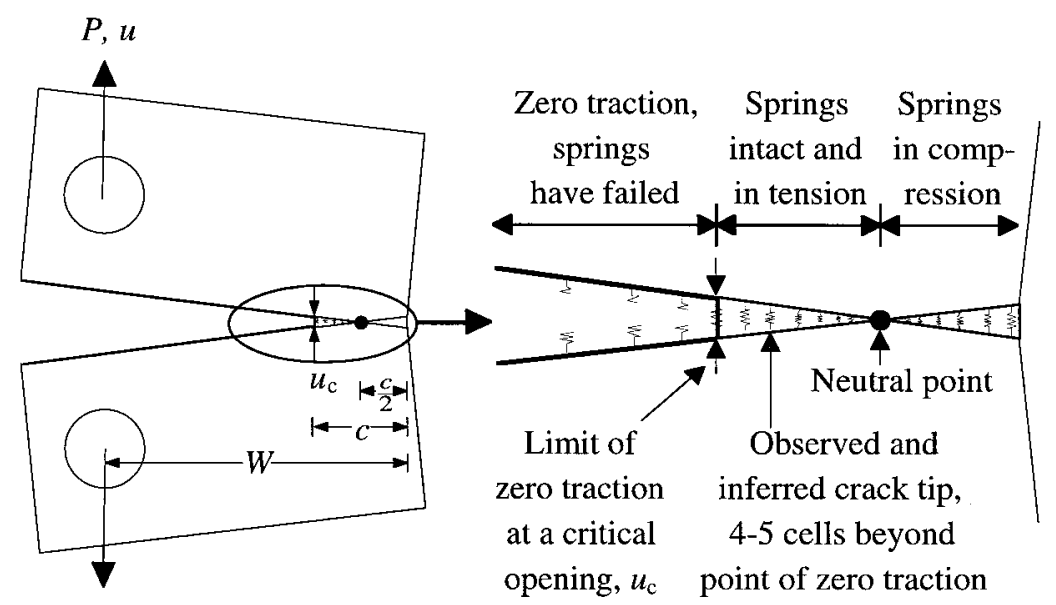

Fig. 12. A line spring model for plastic collapse of the compact tension specimen.

dimensional crack bridging model is adequate to describe the tearing strength of the foam.

An examination of the kinematics of the idealized line spring model in Fig. 12 provides the relation

$$
u=u_{\mathrm{c}}\left(\frac{2 W}{c}-1\right)
$$

We note that a linear relationship is predicted between the load-line displacement $u$ and the ligament size $c$ (and thus the crack length $a$ ). This relationship is compared with typical $c-u$ data from a $0.6 \% \mathrm{Si}$ specimen in Fig. 13(b). For a large crack extension [i.e. for $(2 \mathrm{~W} / \mathrm{c}-1)$ in the range 2.5-4.5] equation (10) suggests a critical crack opening displacement $u_{\mathrm{c}} \approx 0.75 \mathrm{~mm}$. This value is close to the interpolated value of $0.70 \mathrm{~mm}$ for the critical extra displacement in deep notch tests, see Fig. 11(b).

The elimination of $c$ from equations (9) and (10) provides a relation between the load $P$ and the load-line displacement $u$

$$
P=\sigma_{\mathrm{pl}} B W \frac{u_{\mathrm{c}}^{2}}{u\left(u+u_{\mathrm{c}}\right)} .
$$

This relationship is plotted with typical $P-u$ data from a $J$-test in Fig. 13(c); there is fair agreement between the prediction and the experimental data.

\subsection{Comparison of initiation toughness and the crack bridging response}

The line spring model can be used to estimate the initiation toughness $J_{\text {IC }}$ from the measured bridging traction $T$ vs extra displacement response $\Delta u$, as shown in Fig. 11(b). The theory is as follows. We treat the compact tension geometry as a deeply cracked bend specimen, as shown in Fig. 14. A moment per unit thickness $M$ is applied to the ends of the beam, and $\theta$ is the associated load point rotation. Then, following Rice et al. [37] and the discussion of Hutchinson [38], an expression for $J$ is obtained from the $M(\theta)$ relation. Let $\theta_{\mathrm{nc}}$ denote the load point rotation in the absence of a crack
( $a=0)$, and let $\theta_{\text {cr }}$ be the rotation due to the presence of the crack, giving

$$
\theta=\theta_{\mathrm{nc}}+\theta_{\mathrm{cr}}
$$

Defined in this way, $\theta_{\mathrm{cr}}$ is independent of the length $L$ of the beam. Provided the beam is deeply cracked, we can write

$$
\theta_{\mathrm{cr}}=f\left(\frac{M}{\sigma_{0} c^{2}}\right)
$$

where $\sigma_{0}$ is some appropriately defined yield strength, and $f$ is a non-dimensional function relating the dependent variable $\theta_{\text {cr }}$ to the non-dimensional group $M / \sigma_{0} c^{2}$. Then, $J$ is given by

$$
J=\frac{2}{c} \int_{0}^{\theta^{*}} M\left(\theta_{\mathrm{cr}}\right) \mathrm{d} \theta_{\mathrm{cr}}
$$

for an end rotation $\theta_{\mathrm{cr}}=\theta^{*}$, and for a wide range of constitutive behaviours. This expression for $J$ has the simple interpretation of $2 / c$ times the area under the $M$ vs $\theta_{\text {cr }}$ curve up to the rotation $\theta^{*}$ of interest. It remains to stipulate equation (13). We can derive this relation for the case of an idealized line spring model, by treating the arms of the deeply cracked beam as rigid bodies, with a line of springs connected across the ligament of the beam. The springs are endowed with a normal traction $T$ vs extra displacement response $\Delta u$, along the lines given by the tests on deep edge notch specimens in tension and in compression, see, for example, Fig. 11(a). We simplify the analysis considerably by assuming that $T$ is an odd function of $\Delta u$; then, the ligament of the deeply cracked beam is in a state of pure bending, with the neutral point at mid-depth. On placing the origin of the co-ordinate frame $(x, y)$ at the neutral point, the bending moment $M$ can be written as

$$
M\left(\theta_{\mathrm{cr}}\right)=2 \int_{0}^{c / 2} T(\Delta u) x \mathrm{~d} x
$$

where 


$$
\Delta u=\theta_{\mathrm{cr}} x .
$$

An expression for the initiation toughness $J_{\text {IC }}$ follows by substituting equations (15) and (16) into

(a)

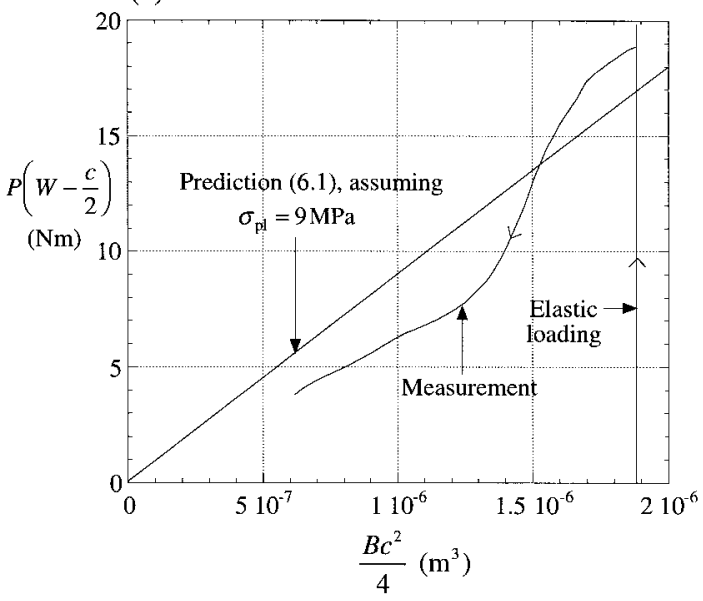

(b)

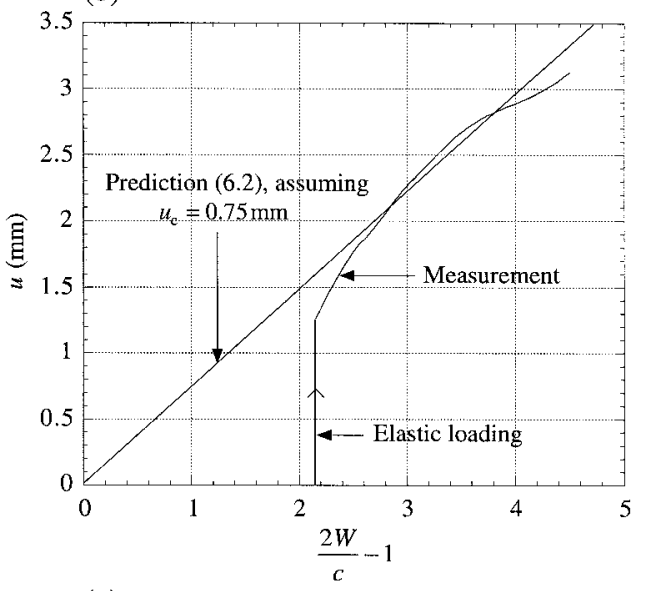

(c)

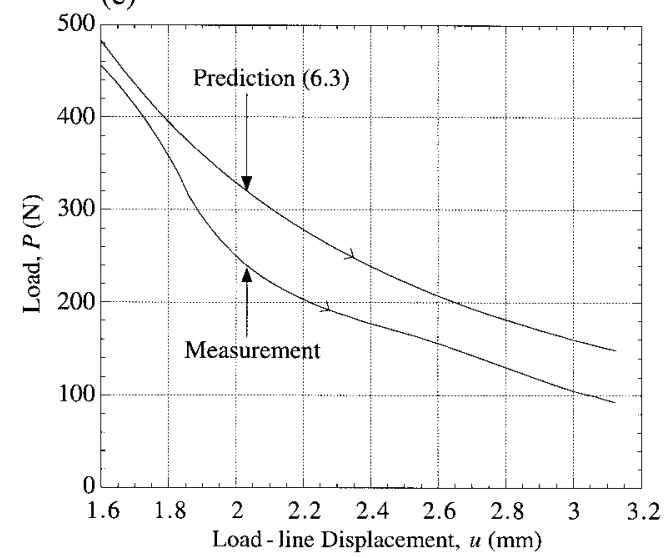

Fig. 13. (a) Predicted yield strength $\sigma_{\mathrm{pl}}$ of $\mathrm{Al}-\mathrm{Mg} 1-\mathrm{Si} 0.6$ from equation (9). Compact tension specimen with $\bar{\rho}=0.27$. (b) Predicted critical crack opening displacement $u_{\mathrm{c}}$ of $\mathrm{Al}-\mathrm{Mg} 1-\mathrm{Si} 0.6$ from equation (10). Compact tension specimen with $\bar{\rho}=0.27$. (c) A comparison of the measured load-displacement curve with the prediction, equation (11), for $\mathrm{Al}-\mathrm{Mg} 1-\mathrm{Si} 0.6$ with $\bar{\rho}=0.27$. The prediction assumes $\sigma_{\mathrm{pl}}=9 \mathrm{MPa}$ and $u_{\mathrm{c}}=0.75 \mathrm{~mm}$. equation (14), and by swapping the order of integration to give

$$
J_{\mathrm{IC}}=\frac{2}{\Delta u^{*}} \int_{0}^{\Delta u^{*}} W(\Delta u) \mathrm{d} \Delta u
$$

where the energy absorbed in the springs $W$ at a displacement $\Delta u$ is

$$
W(\Delta u) \equiv \int_{0}^{\Delta u} T(u) \mathrm{d} u .
$$

In order to evaluate $J_{\mathrm{IC}}$ in terms of the area $W\left(\Delta u^{*}\right)$ under the crack traction vs extra displacement curve, an explicit relation must be chosen for the crack bridging law, $T(\Delta u)$. It is instructive to assume a power law relation

$$
T(\Delta u)=\sigma_{0} \Delta u^{N}
$$

in terms of the reference strength $\sigma_{0}$ and the power law exponent $N$. Then, equations (17)-(19) give

$$
J_{\text {IC }}=\frac{2}{N+2} W\left(\Delta u^{*}\right) \text {. }
$$

Equation (20) reduces to $J_{\mathrm{IC}}=\frac{2}{3} W\left(\Delta u^{*}\right)$ for the case of a linear crack bridging law, $N=1$, and $J_{\mathrm{IC}}=W\left(\Delta u^{*}\right)$ for the rigid-ideally plastic limit $N=0$; we conclude that the initiation toughness $J_{\text {IC }}$ is of comparable magnitude to the area under the crack bridging law for tension $W\left(\Delta u^{*}\right)$. A comparison of experimental values for $W\left(\Delta u^{*}\right)$ and $J_{\mathrm{IC}}$ can be made for the Alulight foams. For the high density tensile specimen of $\bar{\rho}=0.32$, $W\left(\Delta u^{*}\right)=6.7 \mathrm{~kJ} / \mathrm{m}^{2}$, see Fig. 11(a). The initiation toughness for the onset of tearing from the notch root of a compact tension specimen is obtained by the $J$-value at an inferred crack length of $4 \mathrm{~mm}$, as discussed in Section 3.7. Thus, from the curve fits for zero traction toughness, equation (8), $J_{\text {IC }}$ equals $6.6 \mathrm{~kJ} / \mathrm{m}^{2}$ for a relative density $\bar{\rho}=0.32$; we conclude that $J_{\mathrm{IC}} \approx W\left(\Delta u^{*}\right)$. This relationship was found to hold, within scatter, for foams of all relative densities investigated; consequently, the zero traction $J_{\text {IC }}$ curve from Fig. 10(a) can be interpreted as a plot of the variation of $W\left(\Delta u^{*}\right)$ with $\bar{\rho}$.

The line spring model predicts a horizontal $J-\Delta a$ curve: once crack extension has initiated at $J=J_{\text {IC }}$ the crack advances at constant $J$. Recall from Section 3.7 that the small positive slope of the measured $R$-curve is thought to be due to non-proportional loading, a feature not captured by the one-dimensional line spring model.

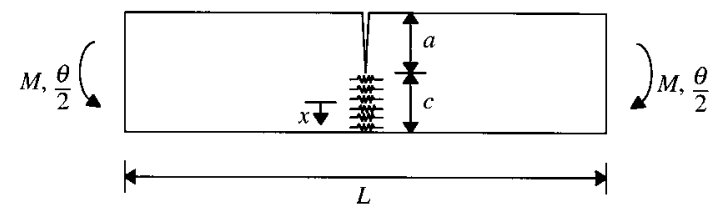

Fig. 14. A deeply cracked bend specimen. 


\section{OPEN-HOLE TENSILE AND COMPRESSIVE STRENGTH}

Specimens containing a single central hole of diameter $D$ in the range $2-8 \mathrm{~mm}$ were tested in order to investigate the sensitivity of tensile and compressive strength to the presence of an open hole, see Fig. 15. The specimens, of length $L=70 \mathrm{~mm}$, width $W=20 \mathrm{~mm}$ and thickness $B \approx 7.5 \mathrm{~mm}$ were manufactured from the $0.6 \% \mathrm{Si}$ foam.

The effect of hole diameter $D$ on the gross tensile and compressive yield strengths are summarized in Fig. 15; here, the gross-section yield strength $\sigma_{\mathrm{n}}$, normalized by the unnotched yield strength $\sigma_{\mathrm{pl}}$ for the same relative density, is plotted against the ratio of the hole diameter $D$ to the specimen width $W$. In tensile tests the gross-section yield strength is taken as the fracture strength; in compression tests it is taken as the plateau strength. The unnotched yield strengths of the specimens have been measured in independent uniaxial tests reported in Ref. [18]. Optical and SEM micrographs revealed qualitatively similar crack initiation and propagation behaviours in tension to those observed in the compact tension fracture specimens. It is clear from Fig. 15 that Alulight is notch insensitive for the hole sizes considered, with the net section strength equal to the uniaxial yield strength in both tension and compression. The foam has sufficient ductility to diffuse the elastic stress concentration at the hole. The results shown in Fig. 15 are for loading in the longitudinal direction of the foamed plates; a similar response was observed in the transverse direction.

\section{CONCLUDING REMARKS}

The toughness of Alulight closed cell aluminium alloy foams has been measured and interpreted in terms of the microstructure. It is found that a low silicon content produces a tougher foam. Compact tension fracture specimens suffer full plastic collapse

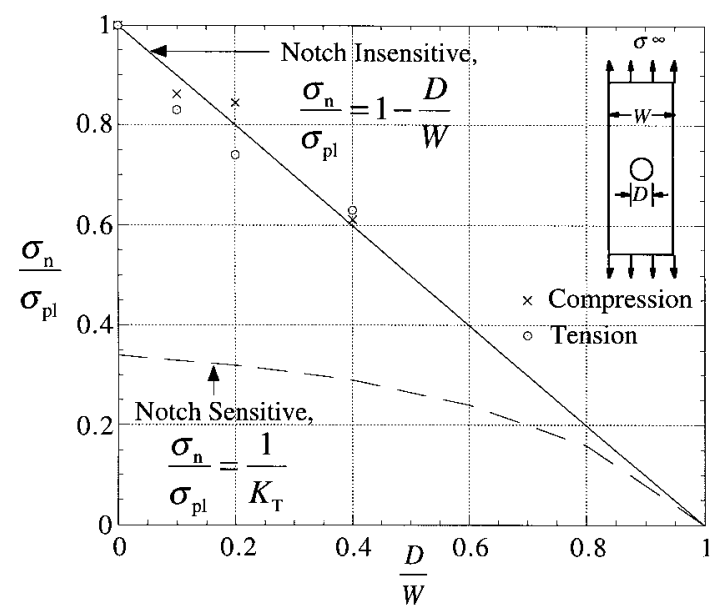

Fig. 15. Open-hole strength in tension and compression for the longitudinal orientation. Al-Mg1-Si0.6 with $\bar{\rho}=0.25-0.35$. across the uncracked ligament, and cell edges bridge the crack behind the observed crack tip; the length of this bridging zone is approximately four cells. Double edge notch specimens were used to measure the crack bridging law in both tension and compression, and a simplified non-linear line spring model was used to characterize crack growth in the compact tension specimens. The area under the tensile traction vs extra displacement curve for the deep notch tests is in approximate agreement with the measured initiation toughness $J_{\text {IC }}$ for the same relative density of foam. Both the plane-strain fracture toughness and the unloading modulus increase with relative density; these relationships can be adequately described by power law fits. Tensile and compressive tests on specimens containing an open hole revealed that the net section yield strength equals the unnotched strength of uniaxial specimens: the material behaves in a notch insensitive manner.

Acknowledgements - The authors are grateful to DARPA ONR for their financial support through MURI grant number N00014-1-96-1028 on the Ultralight Metal Structures project at Harvard University, to F. Simancik of Mepura for supplying the Alulight foams, to T. J. Lu and I. Schmidt for many constructive comments, and to A. Heaver and S. Marshall for their technical assistance.

\section{REFERENCES}

1. Baumeister, J. and Schrader, J., German Patent DE $4101630,1991$.

2. Davies, G. J. and Zhen, S., J. Mater. Sci., 1983, 18, 1899.

3. Akiyama, S., Imagawa, K., Kitahara, A., Nagata, S. Morimoto, K., Nishikawa, T. and Itoh, M., U.S Patent 4,713,277, 1987.

4. Sang, H., U.S. Patent 5,334,236, 1994.

5. Thornton, P. H. and Magee, C. L., Metall. Trans. A, 1975, 6A, 1253.

6. Niebylyski, L. M. and Fanning, R. J., SAE Trans., 1973, 81, 1676

7. Lu, T. J., Stone, H. A. and Ashby, M. F., Acta mater., 1998, 46, 3619.

8. Koch, A., Thompson, M. and Nardone, V., Proc. 4th International Conference on Aluminium Alloys, Atlanta, GA, 1994, p. 387.

9. Hess, A., Lu, T. J. and Ashby, M. F., CVED/CMICROMECH/TR. 11, 1998.

10. Gibson, L. J. and Ashby, M. F., Cellular Solids. Structures and Properties, 2nd edn. Cambridge University Press, Cambridge, 1997.

11. Suh, K. W. and Skochdopole, R. E., Foamed plastics, in Encyclopedia of Chemical Technology, Vol. 2, 3rd edn. Wiley, New York, 1980.

12. Suh, K. W. and Webb, D. D., Cellular materials, in Encyclopedia of Polymer Science, Vol. 2, 3rd edn. Wiley, New York, 1985.

13. Wendle, B. C., Engineering Guide to Structural Foams. Technomic Publishing Co., Westport, CT, 1976.

14. Hilyard, N. C., Mechanics of Cellular Plastics. Applied Science, U.K., 1982.

15. Hilyard, N. C. and Cunningham, A., Low Density Cellular Plastics: Physical Basis of Behaviour. Chapman \& Hall, London, 1994. 
16. Banhart, J. (ed.), Proc. Metallschaume Conference on Metal Foams, Bremen, 6-7 March. MIT Publications, Bremen, 1997.

17. Ashby, M. F., Evans, A. G., Hutchinson, J. W. and Fleck, N. A., Metal Foams: A Design Guide, CUED/ C-MICROMECH/TR.3, 1998.

18. McCullough, K. Y. G., Fleck, N. A. and Ashby, M. F, Acta mater., 1999, 47, 2323.

19. Brezny, R. and Green, D. J., J. Am. Ceram. Soc., 1989, 72, 1145

20. Huang, J. S. and Gibson, L. J., Acta mater., 1991, 39, 1627.

21. Gradinger, R., Simancik, F., Degischer, H. P. and Krizst, B., Unpublished research, 1998.

22. Standard Test Method for Plane-Strain Fracture Toughness of Metallic Materials, ASTM E399-90, 1990.

23. Standard Test Method for $J_{\mathrm{IC}}$, A Measure of Fracture Toughness, ASTM E813-89, 1989.

24. Hertzberg, R. W., Deformation and Fracture Mechanics of Engineering Materials, 4th edn. Wiley, New York, 1996.

25. Fleck, N. A., An investigation of fatigue crack closure. Ph.D. thesis, 1984.

26. Halliday, M. D. and Beevers, C. J., The Measurement of Crack Length and Shape During Fracture and Fatigue. EMAS, 1980.

27. Smith, R. A., J. Strain, 1974, 4, 183

28. Irving, P. E. and Kurzfeld, A., Application of the Potential Drop Technique for Crack Length
Measurement to Fracture Toughness Specimens of the CTS Type. Nat. Phys. Lab, 1975.

29. Richards, C. E. and Deans, W. F., The Measurement of Crack Length and Load using Strain Gauges. EMAS, 1980, p. 28.

30. Sugimura, Y., Rabiei, A., He, M. Y., Bart-Smith, H., Grenestedt, J. and Evans, A. G., Acta mater., 1997, 45, 5245 .

31. Hutchinson, J. W. and Paris, P. C., Stability Analysis of J-Controlled Crack Growth, ASTM STP 668, 1979, p. 37.

32. Standard Test Method for Determining $J-R$ Curves, ASTM E1152-87, 1987.

33. Shih, C. F., Dean, R. H. and German M. D., On $J$ controlled growth: evidence, requirements and applications. General Electric Company, T13 Report, 1983.

34. Ernst, H. A., Materials Resistance and Instability Beyond J-Controlled Crack Growth, ASTM STP 803, 1981, p. 191.

35. Fleck, N. A. and Smith, R. A., Powder Metall., 1981, 3, 126.

36. Hart, A,-M., Fleck, N. A. and Ashby, M. F, Acta mater., 1999, 47, 2511.

37. Rice, J. R., Paris, P. C. and Merkle, J. G., Progress in Flaw Growth and Fracture Toughness Testing, ASTM STP 536, 1973, p. 231.

38. Hutchinson, J. W., A course on nonlinear fracture mechanics, Dept. Solid Mechanics, Technical University of Denmark, 1979. 